\title{
Pituitary Metastasis From Breast Cancer Presenting as SIADH
}

\author{
James Orsini $^{\mathrm{a}}$, Adaeze Nwosu-Iheme ${ }^{\mathrm{a}, \mathrm{c}}$, Sowmini Medavaram ${ }^{\mathrm{b}}$, Alice J. Cohen ${ }^{\mathrm{a}}$
}

\begin{abstract}
Pituitary metastasis is rare and unusual but can be seen in advanced breast and lung cancers with patients presenting with symptoms that range from mild headaches to seizures and altered mental status due to hyponatremia. A 53-year-old female with invasive ductal carcinoma of the left breast which was hormone positive, presented 5 years after completion of therapy with a dry cough, hyponatremia, weakness and visual disturbance. An MRI of the brain revealed a pituitary mass, compressing the optic chiasm. Hyponatremia was found to be due to SIADH. Biopsy confirmed metastatic breast carcinoma. Metastatic spread to the pituitary gland is rare (comprising less than $1 \%$ of pituitary tumors) but can occur in patients with advanced breast and lung cancers. Presentation with SIADH has previously not been reported with metastases due to breast cancer. Diagnosis may require biopsy or resection of the pituitary. Despite aggressive intervention, the prognosis is poor.
\end{abstract}

Keywords: Breast cancer; Pituitary neoplasm; SIADH; Metastasis

\section{Introduction}

Pituitary metastases (PMs) are rare consisting of about 1\% of pituitary tumors, with the most common primary sites of origin being breast, lung and the gastrointestinal tract [1, 2]. Patients can present with symptoms consistent with hypopituitarism and optic nerve compression causing headaches, visual field deficits, diabetes insipidus, hypoglycemia and electrolyte derangement [1-3]. More commonly, PM affects the elderly with multiple sites of disease; however, occasionally it is the

Manuscript accepted for publication July 23, 2015

aDivision of Hematology and Oncology, Newark Beth Israel Medical Center, Newark, NJ, USA

bDivision of Internal Medicine, Newark Beth Israel Medical Center, Newark, NJ, USA

'Corresponding Author: Adaeze Nwosu-Iheme, Division of Hematology and Oncology, Newark Beth Israel Medical Center, Newark, NJ, USA. Email: adaeze.iheme@gmail.com

doi:http://dx.doi.org/10.14740/jem295w first site of disease [1]. It can be difficult to diagnose PM as the symptoms are non-specific and there is no significant radiographic difference when compared to primary pituitary tumors. Pathological findings, therefore, become crucial to the diagnosis. We present a case of a pituitary mass found in a 53-year-old female in remission for 5 years after a diagnosis of stage IIIA hormone positive breast cancer who presented with hyponatremia.

\section{Case Report}

A 53-year-old female with history of a T2N2M0, stage IIIA, ER and PR positive, HER-2 negative invasive ductal carcinoma of the left breast diagnosed in 2009, previously treated with mastectomy, axillary lymph node dissection, chemotherapy and radiation to the left breast, left axilla, and left supraclavicular area presented with visual disturbance, electrolyte derangement and weakness. Her initial treatment in 2009 consisted of dose dense adriamycin $\left(60 \mathrm{mg} / \mathrm{m}^{2}\right)$ and cyclophosphamide $\left(600 \mathrm{mg} / \mathrm{m}^{2}\right)$ followed by weekly paclitaxel $\left(80 \mathrm{mg} / \mathrm{m}^{2}\right)$. She went on to receive hormone therapy, initially in the form of a selective estrogen receptor blocker, tamoxifen (20 mg, PO daily) and was later switched to an aromatase inhibitor (AI), letrozole (2.5 mg PO daily) when she reached a menopausal state. She was receiving ongoing surveillance by medical oncology at 6-month intervals; on her most recent visit, she gave a 2-week history of dry cough. She denied any visual distur-

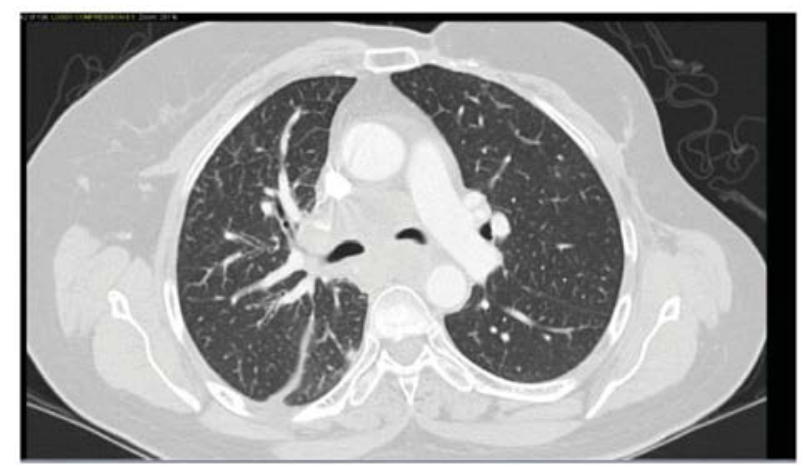

Figure 1. Confluent mediastinal and right hilar adenopathy, likely represent metastatic disease. Peribronchovascular infiltrates in the right lower lobe. 


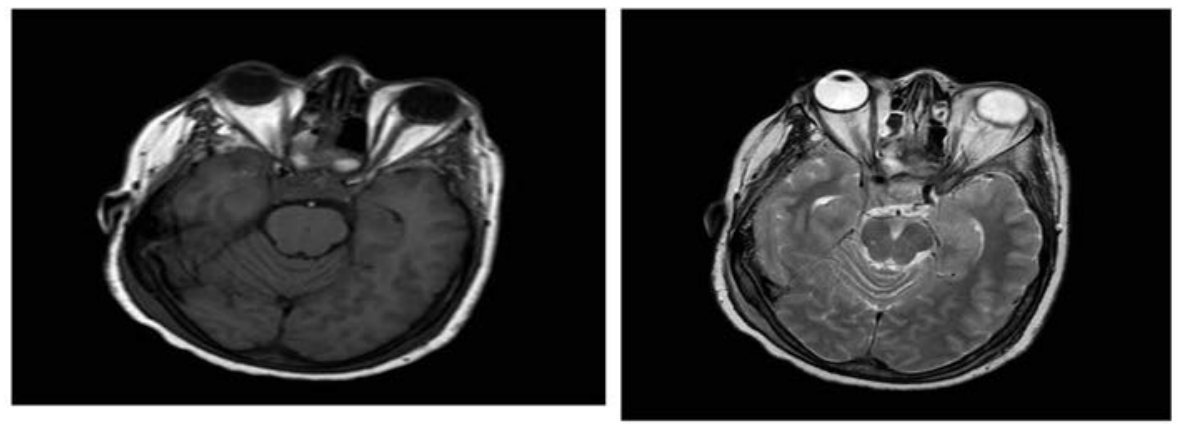

Figure 2. There is a $2.6 \times 1.2 \times 1.3$ sellar mass with intermediate signal intensity on T1 and T2-weighted images inseparable from pituitary gland and compressing optic chiasm. The mass abuts the right cavernous sinus without definite invasion.

bances, weakness, fatigue and confirmed compliance with her AI. Routine lab work revealed mild anemia with hemoglobin of $10.8 \mathrm{~g} / \mathrm{dL}$, a slightly elevated alkaline phosphatase of 159 $\mathrm{U} / \mathrm{L}$ (normal range 0 - $100 \mathrm{U} / \mathrm{L}$ ), and a normal CA 27.29 U/ $\mathrm{mL}(0$ - $38.6 \mathrm{U} / \mathrm{mL})$. Given her presenting complaint of dry cough and elevated alkaline phosphatase in addition to ordering her annual mammogram, a CT of the chest and bone scan were also ordered. She was scheduled to return after her scans were completed, but was admitted to a local hospital 2 weeks after her clinic visit with worsening cough, weakness and fatigue. She was diagnosed with bronchitis and sent home on antibiotics only to return to 3 days later with no improvement of her symptoms and new developments of diffuse headache and blurred vision. Additional testing revealed hyponatremia at $122 \mathrm{mg} / \mathrm{dL}$ and hyperkalemia at $5.5 \mathrm{mg} / \mathrm{dL}$; CT chest (Fig. 1) revealed multiple nodular opacities in the left upper lobe of the lung as well as diffuse adenopathy, and a liver lesion. MRI of the brain (Fig. 2) revealed a $2.6 \times 1.2 \times 1.3 \mathrm{~cm}$ sellar mass with intermediate signal intensity on $\mathrm{T} 1$ and $\mathrm{T} 2$-weighted images inseparable from pituitary gland and compressing the optic chiasm. Initial laboratory work revealed hyponatremia with sodium of $120 \mathrm{mEq} / \mathrm{L}$ (135 - $145 \mathrm{mEq} / \mathrm{L})$, low TSH 0.30 $\mathrm{mIU} / \mathrm{L}$ (0.35 - $5.5 \mathrm{mIU} / \mathrm{L})$, low total T3 $0.38 \mathrm{ng} / \mathrm{mL}$ (0.60 - 1.8 $\mathrm{ng} / \mathrm{mL})$, free T3 $1.2 \mathrm{ng} / \mathrm{mL}$ (2.3 - $4.2 \mathrm{ng} / \mathrm{mL})$, and free T4 0.40
ng/dL (0.89 - $1.76 \mathrm{ng} / \mathrm{dL})$. Additional findings included low LH $2.0 \mathrm{mIU} / \mathrm{mL}(10.0$ - $54.7 \mathrm{mIU} / \mathrm{mL})$ and FSH $14.2 \mathrm{mIU} /$ $\mathrm{mL}(23.0$ - $116.3 \mathrm{mIU} / \mathrm{mL})$ consistent with hypopituitarism. However, ACTH 24 pg/mL (6 - 50 pg/mL), random cortisol 16.8 UG/dL (3 - 23 UG/dL) and prolactin 9.9 ng/mL (2 - 20 ng/ $\mathrm{mL}$ ) levels were normal. Hyponatremia prompted further studies which showed serum osmolarity $249 \mathrm{mmol} / \mathrm{L}$ (280 - 300 $\mathrm{mmol} / \mathrm{L})$, urine osmolarity $753 \mathrm{mmol} / \mathrm{L}$ (300 - 1,000 mmol/L) and urine sodium of 28 indicative of SIADH.

Because of symptoms and fall of her sodium to 118 $\mathrm{mEq} / \mathrm{L}, 3 \%$ hypertonic saline was initiated for a correction of $0.5 \mathrm{mEq} / \mathrm{h}$ with a max correction of $10 \mathrm{mEq} / 24 \mathrm{~h}$. She was also started on decadron $4 \mathrm{mg}$ IV q6h to reduce intra-cerebral swelling and a neurosurgery consult was called. An endobronchial ultrasound (EBUS) (Fig. 3) was performed with biopsy and cytology and immunostains are also shown (Fig. 4) which is positive for pan-CK, ER. The patient thereafter underwent a trans-sphenoid resection of pituitary lesion because of her visual symptoms. The pathology from this lesion is shown (Fig. 5) and was consistent with an ER+ PR+ HER2- metastatic breast lesion.

Postoperatively there was some improvement in her symptoms and the electrolyte-hormone imbalance was corrected and she was discharged home.

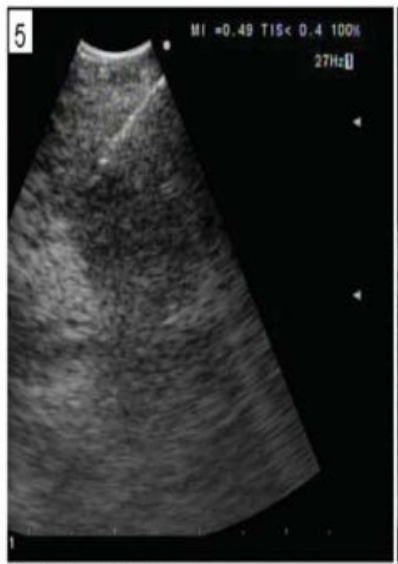

Mediastinal Mass Bx

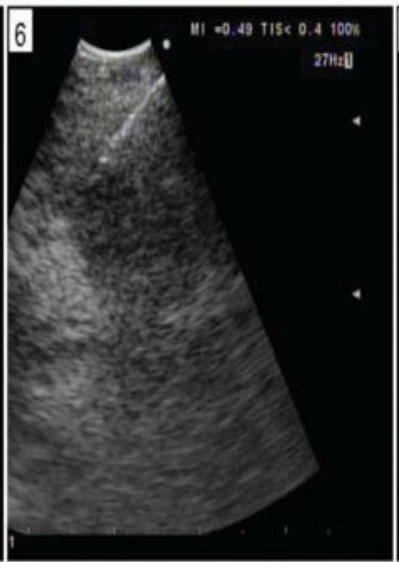

06/07/2013

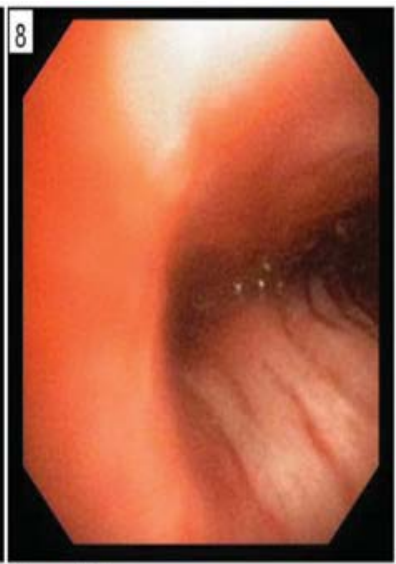

View at Carina

Figure 3. EBUS showing the biopsy taken from right hilar lymph node. 


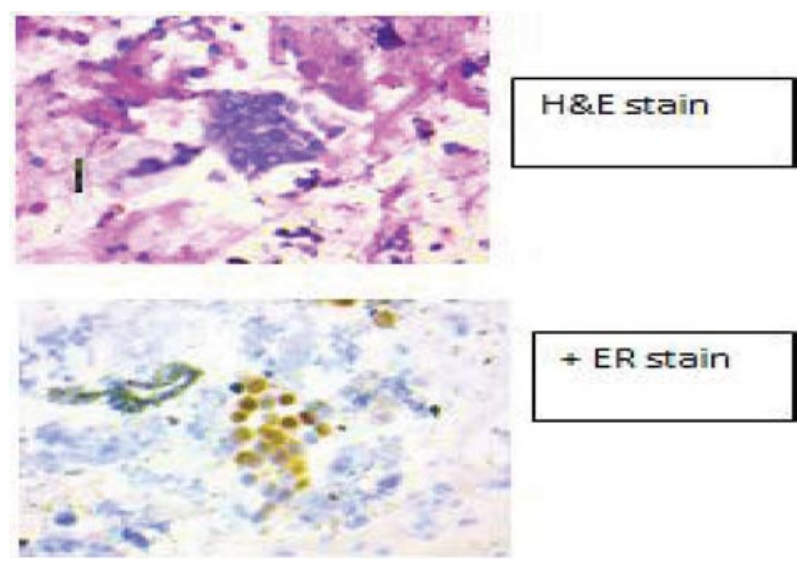

Figure 4. Immunostains from EBUS showing ER+.

The patient then presented with right-sided weakness and confusion. An MRI revealed dural enhancement, parenchymal lesions, metastatic emboli and leptomeningeal involvement. She was started on decadron $10 \mathrm{mg}$ IV then $8 \mathrm{mg}$ IVq6h to reduce edema. The plan at that time was to start capcitabine and have omaya reservoir placed for intrathecal methotrexate but her thrombocytopenia prompted investigation of the bone marrow for circulating malignant cells.

Bone marrow biopsy (Fig. 6) revealed a slightly hypocellular marrow with trilineage hematopoiesis, normal M:E ratio with clusters of atypical epithelial cells (cytokeratin+, ER+) consistent with metastatic carcinoma of the breast. She was started on xeloda $1,000 \mathrm{mg} / \mathrm{m}^{2}$ PO BID D1-14 q21 day cycle. Over the next 2 days worsening confusion developed and a head CT (Fig. 7) showed interval moderate bilateral subdural effusions likely related to progression of leptomeningitis and associated early descending transtentorial herniation bilaterally. She was transferred to the ICU and prepped for cranial decompression but she expired prior to further intervention.

\section{Discussion}

Metastatic disease to the hypothalamus and pituitary gland is rare and accounts for $1-2 \%$ of sellar masses; as the prevalence of solid tumors increases, so may sites of unusual metastasis [3]. PMs typically affect elderly patients in the sixth or seventh decade of life with no clear sex predominance [2, 3]. Symptoms occur in about $7 \%$ of patients and include diabetes insipidus, visual field defects, retro-orbital pain, anterior pituitary dysfunction and opthalmoplegia [1].

In women, metastasis to the pituitary most commonly occurs from a primary breast cancer and in men, from a primary lung cancer. Other primary sites of metastasis include renal, prostrate, thyroid, gastrointestinal, and melanoma; yet lung and breast made up more than $60 \%$ of the cases in one literature review $[1,2]$. Still in about $3 \%$ of those patients, the primary tumor remains undetected even after intensive investigation [1].

There are three main active hypotheses to explain metastases to the pituitary: 1) hematogenous spread, 2) dissemination via portal venous system and 3 ) direct invasion from pituitary parenchyma. Others have theorized that extension from bone metastasis and/or meningeal spread through suprasellar cistern as causes [4-6]. The most common sign of PM is central

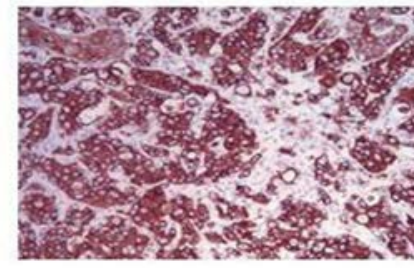

Cytokeratin 7 which is normally present in a tumor of mammary origin and not in pituitary tumors

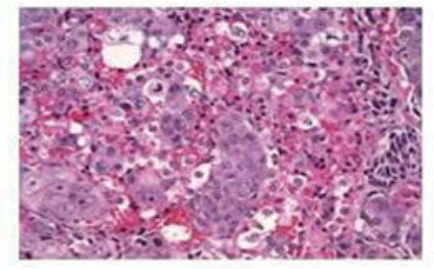

Nest of metastastic cells showing anaplasia and mitotic figures among normal adenohypophysis cells

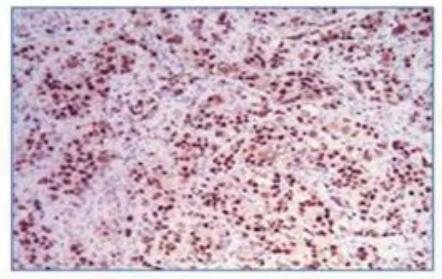

+ ER stain

Figure 5. Pituitary mass histology revealed metastatic breast cancer with cytokeratin, ER, PR positive and Her 2 negative staining. 

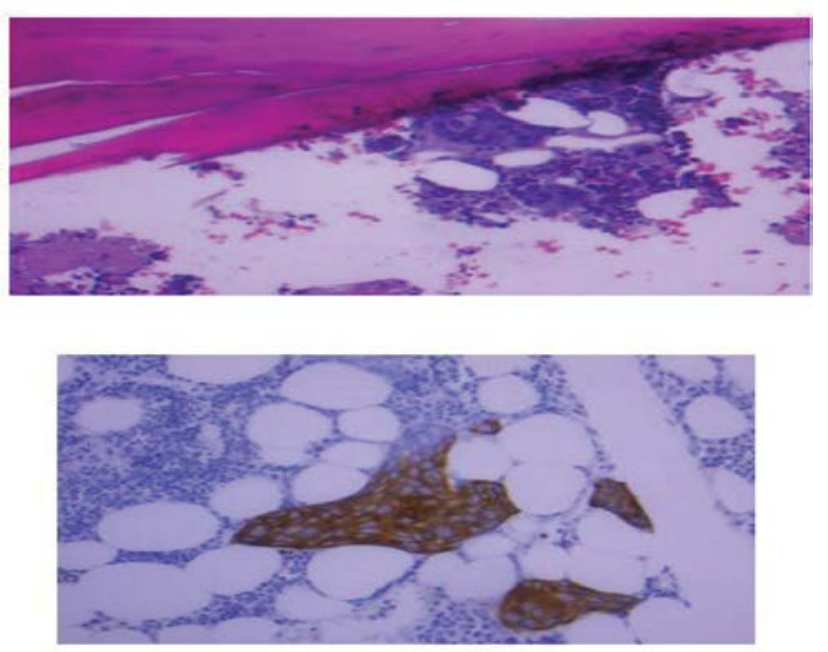

Figure 6. Bone marrow biopsy showed hypocellular marrow with normal M:E ratio with clusters of atypical cells positive for cytokeratin and ER receptors.

diabetes insipidus (DI), a reflection of posterior pituitary lobe involvement and subsequent $\mathrm{ADH}$ dysregulation. The posterior lobe of the pituitary has a larger area of contact with dura mater and has direct arterial blood flow where the anterior lobe lacks a direct arterial blood supply, perhaps strengthening the hypothesis of metastases via hematogenous spread. Central DI is an uncommon complication of pituitary adenomas, manifesting in less than $1 \%$ of cases [1].

In a review of 190 symptomatic patients with PMs, the most common presentation was central DI, present in 86 of those patients, accounting for $45.2 \%$ of the cohort [1]. Other symptoms previously mentioned, including visual field defects and retro-orbital pain, are non-specific and can mimic any mass lesion in that area. Central DI is said to be the most important criterion for differentiating PM from adenomas [7].

SIADH is a rare presentation of PM. It occurs due to increased production of vasopressin. Alternatively, it may be secondary to ectopic production from the tumor. The source of ectopic ADH is unlikely to have been from the lung metastasis in our patient as the immunohistochemical stains were negative for ADH production. Our patient is unique as she had features of hypopituitarism and SIADH as seen in pituitary adenomas rather than DI which is more common with PM [8]. Additionally, our patient presented with headache, fatigue, visual field defects, central hypothyroidism and low FSH and LH which are more common findings of a pituitary adenoma than in PMs. This made a diagnosis more challenging and neurosurgical intervention was necessary for both symptom control and pathologic diagnosis. Non-invasive imaging such as CT and MRI has limitations; the former is not useful in differentiating benign from malignant tumors, MRI is more sensitive and specific, and depending on degree of enhancement and surrounding features like dural or leptomeningeal involvement, seen in our case, can infer possibility of metastatic lesion yet can only confirm a micro- or macroadenoma $[9,10]$.

SIADH has been reported due to chemotherapy in women with metastatic breast cancer including women treated with

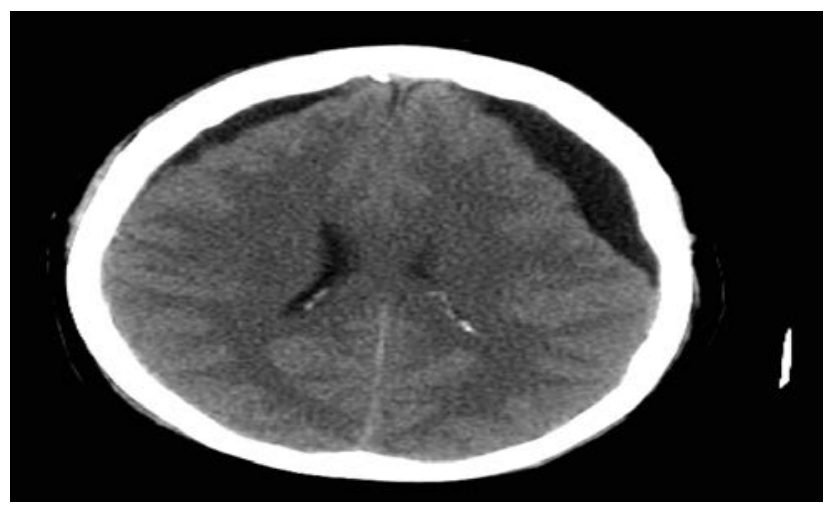

Figure 7. CT head showing moderate bilateral subdural effusions with early descending transtentorial herniation bilaterally.

vinblastine, docetaxel, vinorelbine, and carboplatin [11-14]. Our patient was not actively receiving chemotherapy at the time of her presentation and therefore chemotherapy was not the cause of her SIADH.

Metastasis to the pituitary carries with it a poor prognosis with mean survival in one clinical series being $6-7$ months $[1,5]$. A review of the literature found that of 72 patients with PM only 10\% survived more than 1 year after diagnosis and the longest surviving patient was 3 years [15]. Worse outcomes were seen in patients older then 65 , those who had metastasis from small cell lung cancer, and those developing a PM lesion within 1 year of diagnosis [1]. Our patient expired with leptomeningeal involvement and bleeding, complications of more wide spread metastasis within the brain and not from complications of the pituitary lesion itself, suggesting that PMs may represent a more ominous sign of wide spread CNS involvement.

Treatment modalities include chemotherapy, radiation therapy, surgical resection, stereotactic radiosurgery (SRS) or combination of the above. Surgical resection prior to fractionated RT is recommended if no known diagnosis of systemic cancer is present. Our patient had transsphenoidal resection of this pituitary lesion, despite known metastatic disease in the mediastinum, in an attempt to control active symptoms and to confirm metastases to the pituitary as prognosis from pituitary adenoma is vastly different from pituitary metastasis $[1,4,16]$.

In summary, we believe this is the first report of breast cancer with metastases to the pituitary gland presenting as SIADH. PM can mimic pituitary adenomas on both imaging and laboratory findings. Similar to those patients with metastases from other sites, the prognosis is poor and despite resection of the pituitary gland and control of SIADH, survival is short.

\section{Competing Interests}

The authors declare that they have no competing interests.

\section{References}

1. Komninos J, Vlassopoulou V, Protopapa D, Korfias S, 
Kontogeorgos G, Sakas DE, Thalassinos NC. Tumors metastatic to the pituitary gland: case report and literature review. J Clin Endocrinol Metab. 2004;89(2):574-580.

2. Kim YH, Lee BJ, Lee KJ, Cho JH. A case of pituitary metastasis from breast cancer that presented as left visual disturbance. J Korean Neurosurg Soc. 2012;51(2):94-97.

3. Spinelli GP, Lo Russo G, Miele E, Prinzi N, Tomao F, Antonelli M, Giangaspero F, et al. Breast cancer metastatic to the pituitary gland: a case report. World J Surg Oncol. 2012;10:137.

4. Zager EL, Hedley-Whyte ET. Metastasis within a pituitary adenoma presenting with bilateral abducens palsies: case report and review of the literature. Neurosurgery. 1987;21(3):383-386.

5. Max MB, Deck MD, Rottenberg DA. Pituitary metastasis: incidence in cancer patients and clinical differentiation from pituitary adenoma. Neurology. 1981;31(8):9981002.

6. Branch CL, Jr., Laws ER, Jr. Metastatic tumors of the sella turcica masquerading as primary pituitary tumors. J Clin Endocrinol Metab. 1987;65(3):469-474.

7. Schubiger O, Haller D. Metastases to the pituitary--hypothalamic axis. An MR study of 7 symptomatic patients. Neuroradiology.1992;34(2):131-134.

8. Walid MS, Troup EC, Robinson JS, Jr. Brain metastasis from thymic carcinoma in association with SIADH and pituitary enlargement: a case report. South Med J. 2008;101(7):764-766.

9. Ntyonga-Pono MP, Thomopoulos P, Luton JP. [Pituitary metastases. 3 cases]. Presse Med. 1999;28(29):15671571.

10. Stein AL, Levenick MN, Kletzky OA. Computed tomography versus magnetic resonance imaging for the evaluation of suspected pituitary adenomas. Obstet Gynecol. 1989;73(6):996-999.

11. Turner N, Stewart J, Barnett F, White S. Syndrome of inappropriate anti-diuretic hormone secretion secondary to carboplatin after docetaxel-carboplatin-trastuzumab combination for early stage HER-2 positive breast cancer. Asia Pac J Clin Oncol. 2012;8(3):e9-e11.

12. Canzler U, Schmidt-Gohrich UK, Bergmann S, Hanseroth K, Gatzweiler A, Distler W. Syndrome of inappropriate antidiuretic hormone secretion (SIADH) induced by vinorelbine treatment of metastatic breast cancer. Onkologie. 2007;30(8-9):455-456.

13. Langer-Nitsche C, Luck HJ, Heilmann M. Severe syndrome of inappropriate antidiuretic hormone secretion with docetaxel treatment in metastatic breast cancer. Acta Oncol. 2000;39(8):1001.

14. Fraschini G, Recchia F, Holmes FA. Syndrome of inappropriate antidiuretic hormone secretion associated with hepatic arterial infusion of vinblastine in three patients with breast cancer. Tumori. 1987;73(5):513-516.

15. Morita A, Meyer FB, Laws ER, Jr. Symptomatic pituitary metastases. J Neurosurg. 1998;89(1):69-73.

16. Adelson RT, DeFatta RJ, Miles BA, Hoblitt SL, Ducic Y. Metastatic breast cancer of the oral cavity. Am J Otolaryngol. 2005;26(4):279-281. 